\title{
ANÁLISIS COMPARATIVO DE CONFLICTOS TERRITORIALES: EL CASO DE POBLATS MARÍTIMS (VALENCIA, ESPAÑA) Y EL DISTRITO SUD-OUEST (MONTREAL, CANADÁ)
}

\author{
Luis del Romero Renau \\ Departament de Geografia, Universitat de València, \\ luis.romero@uv.es
}

\section{RESUMEN}

En este trabajo se realiza un análisis comparativo de conflictos territoriales en dos distritos de dos ciudades distintas: Valencia en España y Montreal en Canadá. Se trata de dos espacios urbanos industriales en plena transformación física, lo cual ha motivado numerosas protestas y conflictos territoriales. Se construyó en primer lugar una base de datos sistemática de conflictos aparecidos en los últimos 15 años en cada distrito (Poblats Marítims en Valencia y distrito Sud-Ouest en Montreal). A continuación se establecen algunas conclusiones reveladoras sobre la relación entre la emergencia de conflictos territoriales y las características socioeconómicas de los lugares donde éstos emergen.

Palabras clave: conflictos territoriales, lucha de clases, Valencia, Montreal.

\section{ABSTRACT}

This paper makes a comparative analysis of territorial conflicts in two districts in two different cities: Valencia in Spain and Montreal in Canada. These two industrial districts are experiencing a deep physical transformation, which has led numerous protests and locational conflicts To do that, a systematic database of conflicts appeared in the last 15 years in each district (Poblats Maritims district in Valencia and Sud-Ouest in Montreal) was set up. We establish finally some interesting conclusions about the relationship between the emergence

Fecha de recepción: octubre 2012.

Fecha de aceptación: julio 2013. 
of spatial conflicts and the socio-economic background of the areas where these conflicts take place.

Key words: territorial conflicts, class struggle, urban transformations, Valencia, Montreal.

\section{INTRODUCCIÓN}

\section{A la ciudad planificada se opone la ciudad practicada (Delgado, 2005:13)}

La historia nos enseña que el malestar por la ciudad no es un fenómeno reciente. A lo largo de la historia urbana se han sucedido diversas formas de resistencia o protesta frente a las estrategias de apropiación o dominación de la ciudad por parte de las élites. De hecho la crítica a la ciudad es tan antigua como la ciudad misma. En las últimas décadas una de las principales novedades en la acción colectiva en las ciudades ha sido la manera de expresar este malestar urbano: a través de la proliferación de conflictos territoriales y urbanos. En este trabajo pretendemos analizar la proliferación de conflictos en dos distritos de dos ciudades completamente distintas con el fin de avanzar en el conocimiento acerca de las causas y dinámica de estos conflictos: por qué surgen, dónde tienen lugar, cómo se desarrollan y qué relación guardan con las características socioeconómicas del barrio o área territorial donde emergen.

El escenario de estudio serán dos distritos tradicionalmente obreros e industriales de dos ciudades pertenecientes a contextos geográficos muy distintos: Valencia en España y Montreal en Canadá. Con este análisis comparado se pretende demostrar que la dinámica de conflictos es comparable en contextos urbanos bien distintos, como son Montreal y Valencia, ya que se trata de dos ciudades que participan del mismo modo de desarrollo capitalista informacional (Castells, 1997) y que existen vínculos claros entre el surgimiento de conflictos y las características socioeconómicas del lugar donde éstos surgen.

El trabajo aquí expuesto se divide en cuatro secciones: en primer lugar se aborda la discusión de la definición de conflicto territorial o urbano; en segundo lugar se presenta la metodología de trabajo; en tercer lugar presentamos brevemente los casos de estudio: el distrito Sud-Ouest en Montreal y el de Poblats Marítims en Valencia, y por último se muestran los resultados y la discusión finalizando con unas breves notas a modo de conclusión.

\section{CONFLICTOS TERRITORIALES Y URBANOS: DELIMITACIÓN CONCEPTUAL Y METODOLOGÍA}

\section{Conceptualización sobre conflictos territoriales}

El inicio del interés por el estudio de conflictos territoriales en la ciudad contemporánea habría que situarlo como mínimo en Europa Occidental y Norteamérica en la década posterior a la II guerra mundial (Trudelle, 2006: 2184), cuando empiezan a organizarse grupos de ciudadanos, muchos de ellos entonces pertenecientes al movimiento obrero, con el fin de oponerse a determinados proyectos tecnocráticos de reforma urbana de la ciudad capitalista, por su envergadura e impactos sociales, ambientales y sobre el patrimonio (Kohler y Wissen, 2005). Los ciudadanos que participan de estos movimientos demandan servicios urbanos básicos, vivienda y transporte y sobre todo aspiran a ser tratados no como usuarios o sujetos pasivos de la ciu- 
dad, sino como interlocutores válidos en el diseño y gestión de la misma. Estos «movimientos sociales urbanos», según terminología de Castells (Castells, 1977) se encargan de denunciar el procedimiento burocrático, opaco y a veces dictatorial de aprobación de todo tipo de planes y proyectos (Kohler y Wissen, 2005). Se trata de políticas sectoriales desarrollistas de vivienda, infraestructuras y desarrollo industrial que se enmarcan bajo la filosofía del keynesiamo espacial imperante en esta época y que siguen los principios de la carta de Atenas, de crear ciudades modernas y funcionales con segregación de funciones y sin demasiado respeto por el patrimonio construido, ya que se considera obsoleto. El propio Lefebvre comienza a interesarse por la ciudad y se convierte en uno de los teóricos más críticos respecto al urbanismo funcional capitalista, cuando en su pintoresca región natal de Béarn, a raíz de descubrimiento de gas natural, se construye una ciudad completamente nueva para albergar a casi 10000 habitantes-obreros siguiendo criterios funcionales (Gaviria, 1969: 6).

En la década de los setenta aparecen los primeros trabajos que estudian conflictos protagonizados por estos movimientos sociales urbanos y relacionados con los cambios en los usos del suelo (Janelle y Millward, 1977; Ley y Mercier, 1980; Harvey, 1976; Cox, 1978), muchos de ellos de inspiración marxista. Sin embargo en esta década sobrevienen una serie de cambios que acabarán modificando a su vez la dinámica de conflictos urbanos. En primer lugar la irrupción del capitalismo global informacional y la crisis del keynesianismo espacial tras las crisis del petróleo: el abatimiento de todo tipo de barreras administrativas, arancelarias o tecnológicas entre territorios, da lugar a lo que Castells, discípulo de Lefebvre, denomina una nueva fase del capitalismo basado en los flujos, la información y el conocimiento : el capitalismo informacional y mundializado (Castells, 1997), un proceso sin precedentes de «transnacionalización del capital» (Garnier, 2011) que lo vuelve más volátil y veloz que nunca. Como resultado de esta volatilidad, las ciudades compiten crecientemente entre sí por atraerlo y fijarlo en la ciudad, a través de la promoción de nuevos sectores económicos que respondan a los intereses del capital. El abanico de posibilidades es bastante amplio, desde la promoción de universidades hasta competiciones deportivas pasando por museos, parques temáticos o parques tecnológicos (Dachevsky, 2001: 62).

Por otro lado, a partir de las crisis industriales y del petróleo de los 70 comienza el declive del paradigma de gobierno territorial del «keynesianismo espacial» (Brenner, 2004). Los intereses de acumulación del capital, durante decenios «atenuados» por políticas keynesianas de desarrollo del Estado de Bienestar (sanidad, educación, vivienda, derechos laborales y sociales) reaparecen con fuerza a partir de la irrupción del paradigma neoliberal que triunfa desde los años 80 y que implica una desregularización creciente de todas las esferas de poder que ostenta el Estado keynesiano (desde las política monetaria hasta la vivienda) (Marcuse y Van Kempen, 2000; Brenner y Theodore, 2002; Mac Leod, 2002) en un contexto histórico de crisis y decadencia del bloque soviético y de críticas feroces a los gobiernos keynesianos por su excesivo burocratismo e incapacidad de resolver las crisis fiscales e industriales de los 70. Se produce así una paulatina imposición de este paradigma como único camino hacia la generación de riqueza y desarrollo en la ciudad, en esos momentos azotada por problemas de paro crecientes (argumento popularizado con el acrónimo thatcherista T.I.N.A.: there is no alternative) (Minton, 2009 : 9). Como consecuencia, comienza un proceso de desmantelamiento paulatino del Estado de Bienestar especialmente en Reino Unido y EE.UU, dando lugar a una ciudad crecientemente dual y dividida (Marcuse, 1989 ; 1993) y con cada día 
más conflictos. Éste es quizás uno de los procesos clave que acontece en las ciudades de hoy en día: una dualización creciente y crecientemente conflictiva, entre ricos y pobres, entre capitalistas y proletarios, entre la ciudad como «espacio de los flujos» o como «espacio de los lugares» (Castells, 1997), entre la ciudad apropiada por los intereses del capital o de los ciudadanos. Esta dicotomía se refleja en un distanciamiento paulatino entre representantes y representados, un malestar creciente que tiene entre sus manifestaciones más claras la proliferación de conflictos de todo tipo en la ciudad.

Ante estas dinámicas, las clases trabajadoras que siguen habitando la ciudad industrial crecientemente desmantelada, desarrollan estrategias de oposición e identidades de resistencia (Castells, 1997: 84), pero dentro de una sociedad crecientemente posfordista. Estas identidades son el resultado de la construcción de un sentido individual y colectivo a través de determinados atributos culturales o valores postmateriales como la historia, el paisaje, la lengua, la manera de producir y distribuir la riqueza, las tradiciones, las creencias (Giddens, 1997, citado por Nel·lo, 2003), y provocan la movilización de crecientes capas de la población contra proyectos urbanos que responden a los intereses de este nuevo capital global. Mientras que en la ciudad industrial los movimientos sociales urbanos son los protagonistas de muchos conflictos, en la ciudad postfordista son los «nuevos movimientos sociales» (Cruz, 2010: 201) los que comienzan a tomar protagonismo.

Es a partir de los ochenta cuando comienzan a estudiarse los conflictos urbanos, no ya solo dentro de la lógica de la lucha de clases, sino incorporando valores postmateriales propios de estos «nuevos movimientos sociales» como el bienestar, el medio ambiente o la ya referida identidad. En este contexto se acuña el término de conflictos de tipo «NIMBY» o «LULU» (Brion, 1988; Wolsink, 1994; Lober, 1995; Alberdi, 2002) de conflictos que surgen por oposición a un determinado uso del suelo no deseado por sus potenciales efectos sociales y/o ambientales nocivos. Finalmente a partir de finales de los 90 se comienza a reconocer el fenómeno de las protestas ciudadanas ligadas a cuestiones territoriales como «conflictos territoriales» (Cruz, 2010: 208), siendo Nel·lo (2003), uno de los primeros autores que comienza a hablar de «conflictividad espacial» cuyo denominador común es el «uso y gestión del territorio» (Nel·lo, 2003:11). Esta es la concepción básica de conflicto que se sigue en este trabajo, definido como toda situación de confrontación entre al menos dos categorías de actores (entre ellos o actores de un mismo tipo entre sí) cuyos intereses divergen con respecto a la gestión de la ciudad o de un espacio más acotado, especialmente en el momento de planificar nuevos usos del suelo (Nel·lo, 2003; Aznar et al, 2006). Se trata de una visión espacial de los conflictos, que más que oponerse a otras visiones desde el campo de la sociología urbana, la antropología o la política, trata de complementarlas, ya que se centra en los conflictos relacionados con la planificación y gestión de la ciudad en tanto que confrontación de intereses entre actores territoriales (Cruz, 2010:65).

\section{Metodología de trabajo}

La metodología utilizada para el estudio de conflictos territoriales difiere de las tradicionales usadas hasta la fecha para el estudio de fenómenos de este tipo (Muñiz, 2012), ya que se aleja de las técnicas clásicas de investigación social mediante entrevistas y encuestas y se adentra en el terreno de las técnicas cuantitativas mediante S.I.G. y estadística geoespacial. La metodología cuantitativa aquí empleada para el estudio de conflictos fue desarrollada inicial- 
mente por Janelle y Milward y posteriormente adaptada por Trudelle (Janelle y Millward, 1976; Janelle, 1977; Ley y Mercier, 1980; Joerin, 2005). Recientemente ha sido utilizada con éxito para analizar la dinámica de conflictos en dos casos de estudio, uno de ellos en España (Del Romero y Trudelle, 2011; Del Romero y Trudelle, 2012). La fuente primaria de datos ha sido tanto las hemerotecas de dos diarios por cada ciudad estudiada, como los anuarios de noticias. Como fuente complementaria de datos se realizaron numerosas búsquedas en internet sobre conflictos territoriales (blogs, páginas de asociaciones de vecinos, ecologistas, investigadores universitarios), así como consultas a algunos actores clave vía correo electrónico (por ejemplo a responsables de plataformas o asociaciones). El uso de noticias periodísticas como fuente primaria de información posee tanto ventajas como desventajas. Entre sus ventajas se encuentra la cantidad de información que estos medios suministran, y además de manera cronológica, sobre un determinado concepto (Joerin et al., 2005: 325). Entre sus desventajas cabe destacar el carácter parcial e incompleto de su información derivado de un tratamiento de la información que no siempre es neutral. Con el fin de paliar en lo posible estos problemas, se optó por recoger información de conflictos siempre a partir de dos periódicos de carácter local con orientaciones ideológicas distintas (La Presse y Devoir de Montreal y El Levante y Las Provincias en el caso de Valencia) y además omitir de la base de datos todas las noticias de carácter editorial, así como artículos de opinión. En estas fuentes se buscaron artículos y noticias que hicieran referencia a conflictos territoriales desarrollados entre el 1 de enero de 1995 y el 31 de diciembre de 2010, cubriendo un total de 16 años en ambas áreas de estudio.

En total se localizaron 58 conflictos en el área de estudio de Montreal y 40 en Valencia. Como variable de localización se escogió el espacio de intervención (Joerin, 2005), es decir: el espacio estricto que ocupa el proyecto o uso del suelo en conflicto, frente a otros espacios (el espacio de los actores por ejemplo, que varía desde la escala de barrio hasta la escala global). Por cada uno de estos conflictos se recogió además información acerca de su intensidad (medida a partir de la duración en días del conflicto y del número de palabras), los actores que participaron (plataformas ad hoc, administraciones, empresas, asociaciones profesionales), las estrategias de presión empleadas etc. y en paralelo se explotó el Censo de Población y Viviendas de 2001 con el fin de cruzar datos de localización e intensidad de conflictos con datos de tipo socioeconómico a nivel de sección (tasas de paro, nivel socioeconómico, nivel educativo etc.). Con la simple explotación mediante estadística descriptiva ya se pudo avanzar algunas ideas interesantes acerca de las causas y dinámica de conflictos en ambas ciudades. Posteriormente, con el fin de demostrar la existencia de vínculos estadísticos entre la localización e intensidad de conflictos y el nivel socioeconómico por sección se elaboró un test de Chi-cuadrado para cada una de las áreas de estudio (ver anexo). De esta manera se realizó un análisis estadístico simple que muestra unos resultados provisionales de gran interés.

\section{JUSTIFICACIÓN Y DESCRIPCIÓN DE LAS ÁREAS DE ESTUDIO}

En el marco de este trabajo se buscaron dos áreas de estudio distintas para mostrar que pese a las diferencias en cuanto a estructura económica, social y escala urbana, la dinámica de conflictos es comparable entre ciudades no siendo exclusiva de una sola realidad local. Para poder verificar los supuestos planteados al inicio, se escogieron dos distritos urbanos como principal área de estudio. Si bien es cierto que hay una cierta literatura comparativa dentro del campo 
urbanístico entre Montreal y ciudades como Barcelona (pese a que tampoco tienen demasiados rasgos en común más allá de ciertos parecidos de escala urbana y demográficos) (Capel y Linteau, 1998), no existen apenas referencias que comparen esta ciudad con Valencia. En este caso, se trata de una ciudad de tamaño inferior a la de Montreal, pero con algunos rasgos destacados: ambas son ciudades litorales con una cierta base económica común (centro industrial y logístico de exportación de productos agrícolas con un destacado papel del puerto), que han experimentado un gran dinamismo urbanístico hasta la crisis de 2008, con un peso histórico destacado de la iglesia católica, y además con un contexto cultural similar de bilingüismo. Estas similitudes, quizás un poco vagas, son mayores si nos centramos en las dos áreas de estudio que nos ocupan: los distritos de Sud-Ouest en Montreal y de Poblats Marítims en Valencia (en ambos casos se trata de subdivisiones oficiales de la ciudad). La razón de realizar un análisis a escala de distrito y no de ciudad se debe a las limitaciones en extensión del formato de artículo, ya que la metodología de análisis comparativo, estadístico y sistemático de conflictos utilizado aquí a escala metropolitana sería difícilmente resumible en un artículo. Por otra parte, para responder adecuadamente a la pregunta de si la dinámica de conflictos es similar y por qué razones, la escala inframunicipal es idónea para el tratamiento estadístico espacial que se explicará posteriormente. Sin embargo, con el fin de poder comparar la dinámica de conflictos no solo entre dos áreas urbanas, sino dentro de una misma, se han incorporado a los análisis los distritos limítrofes con las áreas de estudio en cada ciudad.

Las áreas principales de estudio (Montreal Sud-Ouest y Valencia Poblats Marítims) son dos distritos con una cantidad de población muy similar (en torno a 70000 habitantes en ambos casos), con un porcentaje importante de inmigrantes residiendo en ellos y con un estatus socioeconómico bajo. Además en ambos casos se trata de piezas urbanas que históricamente han vivido relativamente aisladas de la ciudad central, con lo que han desarrollado una cierta identidad propia basándose en su condición de barrios populares y proletarios. Como áreas secundarias de estudio se optó por escoger el conjunto de distritos que rodean a cada distrito. En ambas ciudades, gran parte de estos distritos contiene barrios de capas mediasaltas o altas de la ciudad, otra similitud notable.

\section{Distrito Sud-Ouest (Montreal): «la ciudad bajo la colina»}

El distrito de Sud-Ouest de Montreal se halla situado en el frente fluvial sur de la isla de Montreal dentro del río San Lorenzo. Como área de estudio secundaria se escogió el conjunto de distritos que rodean a éste último (ver figura 2). El distrito de Sud-Ouest integra diversos barrios obreros históricos ligados a la intensa actividad industrial que se localizaba hasta los años setenta junto al canal Lachine (Saint-Henri o Point-Saint-Charles). Este distrito es considerado como la cuna de la industrialización de Canadá gracias a la construcción en 1826 de este canal que permitía la navegación del río San Lorenzo. A partir de esta época se instalan las primeras industrias pesadas junto a este canal de manera que poco a poco se desarrolla un ingente barrio obrero industrial conocido en el siglo XIX como «el barrio bajo la colina» («the city below the hill»), en contraste con «la ciudad sobre la colina» que era la ciudad de la burguesía, tal y como se describe en el siguiente fragmento:

The city above the hill is the home of the classes. Within its well-built residences will be found the captains of industry, the owners of real estate, and those who labor with brain 
rather than hand. The city below the hill is the dwelling place of the masses, the home of the craftsman, of the manual wage-earner, the real industrial class (P.F.W. Rutherford, 1897: 32)

La «ciudad bajo la colina» poseía ya en el siglo XIX importantes problemas sanitarios, higiénicos y de explotación de la mano de obra, así como carencias de servicios de todo tipo, ya que aún en 1897 solo una familia de cada cuatro tenía lavabos y la tasa de mortalidad era del 44\%o, una de las más altas del país (Rutherford, 1897). Aunque muchas de estas carencias se van resolviendo con el tiempo, a partir de la década de los setenta del siglo XX la crisis industrial golpea duramente a este espacio urbano convirtiéndolo en uno de los más pobres de todo Canadá (Pinnel, 2005). A partir de esta época este distrito comienza una lenta decadencia que aún hoy continúa en gran parte de sus barrios, tal y como se puede mostrar en el cuadro 1 que compara indicadores socioeconómicos entre el distrito Sud-Ouest (área principal de estudio), el conjunto de barrios y distritos adyacentes (área secundaria de estudio) y la media de Montreal.

Frente a esta «ciudad bajo la colina», antiguo barrio obrero hoy azotado por problemas de pobreza y paro, sigue existiendo una «ciudad en la colina», el distrito financiero de Montreal compuesto por los distritos de Ville-Marie y parte de Côte-des-Neiges-NotreDame-de-Grâce, así como sobre todo el municipio de Westmount, uno de los más ricos de la metrópolis. Además circundando el distrito de Sud-Ouest también se encuentran los distritos residenciales de Lasalle, Verdun y Lachine, hoy en día espacios urbanos residenciales de baja densidad para las clases medias. Este conjunto de distritos y barrios constituye el área secundaria de estudio de Montreal.

Figura 1

ÁREA DE ESTUDIO DE MONTREAL, CONSTITUIDO POR EL DISTRITO DE SUD-OUEST ASÍ COMO POR LOS DISTRITOS DE SUS ALREDEDORES VERDUN, LASALLE, LACHINE, CÔTE-DES-NEIGES-NDG, VILLE-MARIE Y EL MUNICIPIO DE WESTMOUNT)

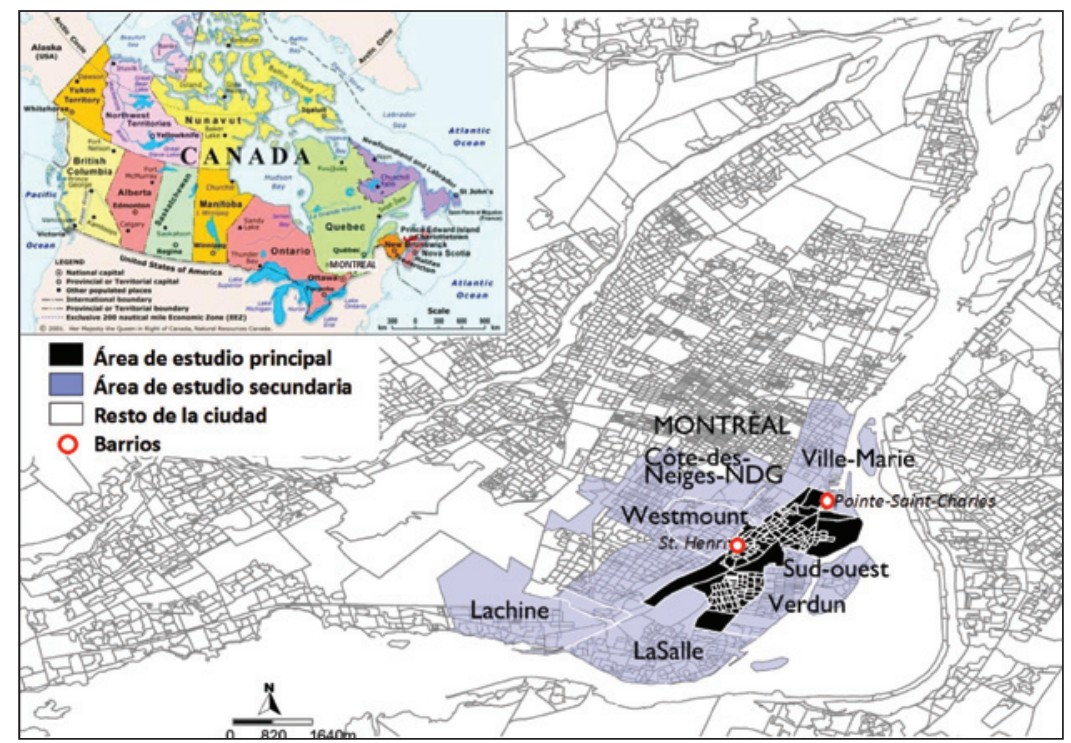


Cuadro 1

DATOS SOCIOECONÓMICOS DEL DISTRITO COMPARADO CON UNO DE SUS BARRIOS MÁS POBRES Y CON LA MEDIA DE MONTREAL

\begin{tabular}{|l|c|c|c|}
\hline & Distrito Sud-Ouest & Distritos adyacentes & Montreal \\
\hline Población sin estudios & $\mathbf{2 7 . 1 \%}$ & $\mathbf{1 3 . 8 \%}$ & $\mathbf{2 9 \%}$ \\
\hline Tasa de paro & $\mathbf{1 6 . 2 \%}$ & $\mathbf{1 1 \%}$ & $\mathbf{1 3 . 2 \%}$ \\
\hline Personas bajo el umbral de pobreza & $\mathbf{3 2 . 8 \%}$ & $\mathbf{1 8 . 3 \%}$ & $\mathbf{2 9 \%}$ \\
\hline Esperanza de vida de hombres & $\mathbf{7 2 . 3}$ & $\mathbf{7 2 . 9}$ & $\mathbf{7 4 . 8}$ \\
\hline Esperanza de vida de mujeres & $\mathbf{7 9}$ & $\mathbf{8 0 . 9}$ & $\mathbf{8 1 . 1}$ \\
\hline
\end{tabular}

Fuentes: Statistique Canada (censo de 2001) y Centro Sanitario y de Servicios Sociales de Verdun/Côte-Saint-Paul, Saint-Henri y Pointe-Saint-Charles (tabla, datos de 2001).

Pese a esta situación, hace ya tiempo que las élites locales, en especial el capital inmobiliario, han puesto los ojos en este distrito. Se trata de un distrito aislado por las vías del tren, pero a apenas un kilómetro del distrito financiero de Montreal, con multitud de espacios para construir si se cuentan las decenas de industrias que aún quedan, muchas de las cuales ya están cerradas, y con el atractivo de contener un canal de navegación que ha sido convertido en canal de recreo, en definitiva un espacio urbano muy apto para la gentrificación. Así desde finales de los noventa se inició un intenso proceso de cambio urbano a partir de proyectos urbanísticos emblemáticos como la rehabilitación del Canal Lachine (2000); rehabilitación de fábricas como la Red Sugar Path o Nordelec para construir apartamentos (años 2000) o un macroproyecto de construcción de un casino y circo permanente de la compañía quebequesa «Cirque du Soleil» al estilo de los casinos de Las Vegas. Estos proyectos han encontrando una feroz resistencia de sus habitantes que temen perder tanto su medio de subsistencia con el cierre de empresas (muchos siguen trabajando en sectores industriales), como su espacio de vida por las consecuencias que estos proyectos conllevan sobre el precio de la vivienda.

\section{Poblats Marítims (Valencia), barrios de pescadores}

Poblats Marítims fue municipio independiente hasta finales del siglo XIX. Se trata de un conjunto de barrios tradicionalmente pesqueros e industriales ligados a las actividades del puerto de Valencia y al mismo tiempo destino de la burguesía valenciana en periodos vacacionales. El escritor valenciano Blasco Ibáñez, residente durante largas temporadas en este distrito, en su novela sobre el barrio del Cabanyal «Flor de Mayo» de 1895 destaca también el contraste entre los alrededores del puerto donde se encuentra «la aristocracia del puerto, los grandes almacenes, las casonas de la burguesía» con respecto a los barrios de Cabanyal y Canyamelar más al norte, barriadas populares de barracas de pescadores, miles de casas multicolores y ruidosas calles. Estos barrios fueron poco a poco integrados en la trama urbana de Valencia, sin embargo debido a su alejamiento respecto al centro de la ciudad (unos $3 \mathrm{~km}$ ) y a su aislamiento (se encontraban encerrados entre las vías del tren y el mar), todo ello propició que hasta hoy en día conserven una fuerte identidad como barrio obrero y de pescadores e incluso una cierta fisonomía de pueblo que no existe en otros barrios de la ciudad. A partir de los años $70 \mathrm{y}$ al igual que en el caso de Montreal, este distrito inicia un largo periodo de declive debido a la crisis industrial y de la pesca, especialmente a partir del cierre de los astilleros del puerto. Se inicia así una lenta decadencia que prosigue años y años sin que desde la administración se aborden 
los crecientes problemas de exclusión y pobreza que azotan a estos barrios. Hoy en día sigue siendo uno de los espacios urbanos más degradados y pobres de la ciudad, tal y como se puede observar en el cuadro 2 donde como en el caso de Montreal, se muestran algunos indicadores socioeconómicos para el distrito de Poblats Marítims (área de estudio principal), los distritos adyacentes (área de estudio secundaria) y la media de Valencia.

Frente a estos espacios en crisis, los distritos de los alrededores de Poblats Marítims poseen características bien diferenciadas. Alboraia es un municipio de l'Horta Nord pegado a Valencia que se ha convertido en refugio de clases medias y altas que residen en la baja densidad; Algirós es un distrito relativamente moderno que inicialmente fue ocupado por trabajadores inmigrantes de la España rural y que hoy en día vive a la sombra de la Universitat de València, de manera que han iniciado un proceso de «estudiantización» o gentrificación surgida a raíz de la ubicación de una universidad (Lees et al., 2008: 131-132). Por último, los distritos de Quatre Carreres y de Camins al Grau son hoy en día dos de los distritos ocupados por las élites burguesas desde fechas recientes. A partir de la operación urbanística de «La Ciutat de les Arts i les Ciències», toda herencia industrial de estos barrios fue borrada (hoy solo quedan como testimonio un par de chimeneas), para construir uno de los principales polos de servicios, esparcimiento y ocio de la ciudad (museos, ópera, dos centros comerciales, parques, Acuarium, juzgados, feria de navidad, conciertos etc.) y por supuesto varias promociones de apartamentos de lujo. Este conjunto de distritos constituye el área secundaria de estudio en Valencia.

$\mathrm{Al}$ igual que en el caso de Montreal, en el caso de Poblats Marítims hace tiempo que el capital inmobiliario ha puesto los ojos en este distrito que contiene la gran ventaja de contener todo el frente marítimo de la ciudad y también espacio para urbanizar en antiguos talleres y almacenes que hoy están cerrados por la situación agónica del sector industrial y pesquera en el distrito, así como la cercanía al nuevo polo de centralidad que supone la Ciudad de las Artes y las Ciencias.

Figura 2

ÁREA DE ESTUDIO DE VALENCIA, EL DISTRITO DE POBLATS MARITIMS Y LOS DISTRITOS DE LOS ALREDEDORES (PINEDO, QUATRE CARRERES, CAMINS AL GRAU, ALGIRÓS Y EL MUNICIPIO DE ALBORAIA)

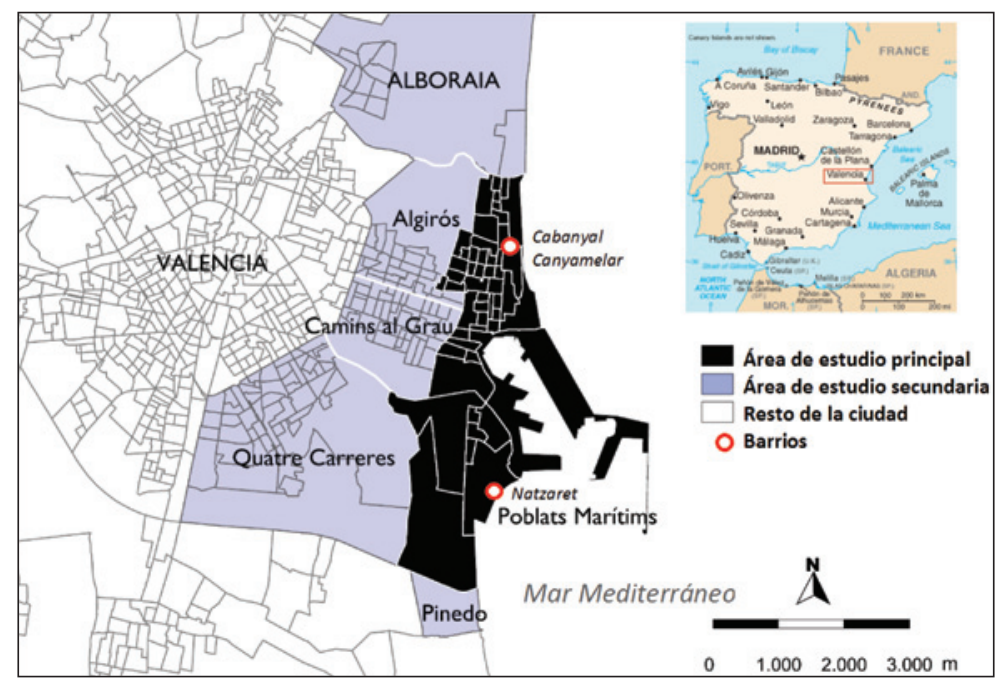


Cuadro 2

DATOS SOCIOECONÓMICOS DEL DISTRITO EN COMPARACIÓN CON LA MEDIA DE VALENCIA

\begin{tabular}{|l|c|c|c|}
\hline & Poblats Marítims & Distritos adyacentes & Valencia \\
\hline Población sin estudios & $\mathbf{2 1 . 8 5 \%}$ & $\mathbf{1 8 . 2 9 \%}$ & $\mathbf{1 7 . 7 1 \%}$ \\
\hline Tasa de paro & $\mathbf{9 . 1 4 \%}$ & $\mathbf{6 . 9 \%}$ & $\mathbf{7 . 8 1 \%}$ \\
\hline Tasa de actividad & $\mathbf{4 4 . 2 3 \%}$ & $\mathbf{5 8 \%}$ & $\mathbf{4 7 . 2 9 \%}$ \\
\hline Esperanza de vida de los hombres & $\mathbf{7 3 . 7 5}$ & $\mathbf{7 6 . 6 7}$ & $\mathbf{7 7 . 3 5}$ \\
\hline Esperanza de vida de las mujeres & $\mathbf{8 1 . 9}$ & $\mathbf{8 3 . 7}$ & $\mathbf{8 3 . 7 9}$ \\
\hline
\end{tabular}

Fuente: Instituto Nacional de Estadística (2001).

Desde los años 90 se han puesto en marcha una gran cantidad de proyectos urbanísticos emblemáticos con el fin de «revitalizar» el frente marítimo según la retórica oficial. Entre estos proyectos destacan aquellos que utilizaron el pretexto de la organización de grandes eventos deportivos para aprobar importantes reformas urbanas como la del puerto en 2003 para la Copa del América celebrada en 2007 y 2009, la transformación de parte de los alrededores del puerto en un circuito de fórmula 1 o la ampliación del puerto deportivo para promover los deportes de vela. Además de sobra es conocido el conflicto territorial del Cabanyal que surge tras la aprobación de un plan para ampliar la avenida Blasco Ibáñez hasta el mar que contemplaría la destrucción de más de 1600 viviendas del barrio, ocupado mayoritariamente por obreros y pescadores jubilados, jóvenes en paro e inmigrantes en una operación con un cierto componente de apuesta por la gentrificación e incluso de «hausmanización» en un barrio histórico: reformar la trama urbana para luchar contra la degradación. Frente a estos proyectos, al igual que en el distrito Sud-Ouest se ha levantado una férrea resistencia por parte de organizaciones vecinales de base obrera, en especial con el caso del Cabanyal.

\section{RESULTADOS Y DISCUSIÓN}

\section{Análisis de resultados}

En total entre las dos ciudades se incorporaron a esta base 1392 artículos de prensa referidos a conflictos. Se recopilaron 30 conflictos en el distrito Sud-Ouest de Montreal (28 más en los distritos limítrofes) y 26 en el distrito de Poblats Marítims (14 más en los distritos limítrofes). Los conflictos más intensos estuvieron relacionados con proyectos de reforma urbana interior (Griffintown en Montreal o la avenida Blasco Ibáñez en Valencia) así como con la ampliación de grandes equipamientos e infraestructuras (autovía Turcot en Montreal y construcción de la ZAL del puerto de Valencia). Tanto en el caso de Montreal Sud-Ouest como en el de Valencia Poblats Marítims, la cantidad de conflictos territoriales aparecidos entre 1995 y 2010 fue muy superior en estos distritos que en los distritos y municipios fronterizos, más aún si comparamos la población. Se trata de una cantidad significativa de conflictos para dos distritos de apenas 70000 habitantes, ya que hay que recordar que éstos son solamente los conflictos territoriales más visibles, es decir, aquellos que han tenido un impacto mediático en la prensa regional los 
que aparecen recogidos en este trabajo. Especialmente llamativo es el caso de Poblats Marítims que en 2001 contenía solamente el 23\% de la población del área total de estudio (este mismo distrito además de los distritos fronterizos) y un $65 \%$ de los conflictos surgidos entre 1995 y 2010. Estos datos indican una mayor concentración de conflictos en distritos con bajo nivel socioeconómico, pero para poder afirmar que existen vínculos estadísticos entre niveles de riqueza y proliferación de conflictos territoriales, utilizamos el test estadístico de Chi cuadrado, que es una de las pruebas estadísticas que con más frecuencia se usa para establecer vínculos estadísticos entre variables cualitativas. En primer lugar se escogió una serie de variables que a priori podrían tener relación con la proliferación de conflictos. Esta serie de variables incluye tanto indicadores que permitirían verificar el supuesto de la relación entre proliferación de conflictos y niveles de paro y pobreza (tasa de paro, nivel de renta para verificar el vínculo entre conflictos y condición social espacio urbano en estudio), así como otros indicadores geográficos y sociodemográficos a través de los cuales se podría construir argumentaciones alternativas o complementarias a esta tesis propuesta (densidad de población, existencia de asociaciones ciudadanas, edad). En el anexo se puede consultar la lista completa de variables obtenida, así como el desarrollo del test de Chi-Cuadrado.

Cuadro 3

TABLA DE SINNTESIS SOBRE EL NÚMERO DE CONFLICTOS HALLADOS POR CIUDAD Y DISTRITO ENTRE 1995 Y 2010 Y EJEMPLOS DE LOS CONFLICTOS MÁS RELEVANTES (ENTRE PARÉNTESIS EL NÚMERO DE ARTÍCULOS DE PRENSA HALLADOS)

\begin{tabular}{|c|c|c|c|}
\hline Montréal & $\begin{array}{c}\mathrm{N}^{\mathbf{a}} \text { de } \\
\text { conflictos }\end{array}$ & Valencia & $\begin{array}{c}\mathrm{N}^{0} \text { de } \\
\text { conflictos }\end{array}$ \\
\hline Distrito de Sud-Ouest & 30 & Distrito de Poblats Marítims & 26 \\
\hline $\begin{array}{l}\text { Distritos del área secundaria } \\
\text { Ville-Marie } \\
\text { Côte-de-Neiges/Notre-Dame de Grâce } \\
\text { Westmount } \\
\text { Verdun } \\
\text { Lasalle } \\
\text { Lachine } \\
\text { Total de conflictos en otros distritos }\end{array}$ & $\begin{array}{c}14 \\
9 \\
1 \\
3 \\
1 \\
0 \\
28\end{array}$ & $\begin{array}{l}\text { Distritos del área secundaria } \\
\text { Alboraia } \\
\text { Algirós } \\
\text { Camins al Grau } \\
\text { Quatre Carreres } \\
\text { Pinedo } \\
\text { Total de conflictos en otros distritos }\end{array}$ & $\begin{array}{l}4 \\
3 \\
3 \\
3 \\
1 \\
14\end{array}$ \\
\hline Total en Montreal & 58 & Total en Valencia & 40 \\
\hline $\begin{array}{l}\text { Conflictos más relevantes en Montreal } \\
\text { (según número de noticias) } \\
\text { - Rehabilitación de barrio histórico de } \\
\text { Griffintown (65) } \\
\text { - Construcción de casino (51) } \\
\text { - Reforma de autovia Turcot (52) }\end{array}$ & & $\begin{array}{l}\text { Conflictos más relevantes en Valencia } \\
\text { (según número de noticias) } \\
\text { - Proyecto de ampliación de avenida } \\
\text { Blasco Ibáñez (134) } \\
\text { - Proyecto Zona de Actividades } \\
\quad \text { Logísticas del puerto (70) } \\
\text { - Ruido de bares y pubs en la } \\
\text { Avenida Blasco Ibáñez(40) }\end{array}$ & \\
\hline
\end{tabular}


Figura 3

DISTRIBUCIÓN DE CONFLICTOS EN MONTREAL

Figura 4

POBLACIÓN EN EL DISTRITO SUD-OUEST (MONTREAL) Y LOS DISTRITOS LIMÍTROFES

Figura 5

DISTRIBUCIÓN DE CONFLICTOS EN VALENCIA

Figura 6

POBLACIÓN EN EL DISTRITO DE POBLATS MARÍTIMS (VALENCIA) Y LOS DISTRITOS LIMÍTROFES
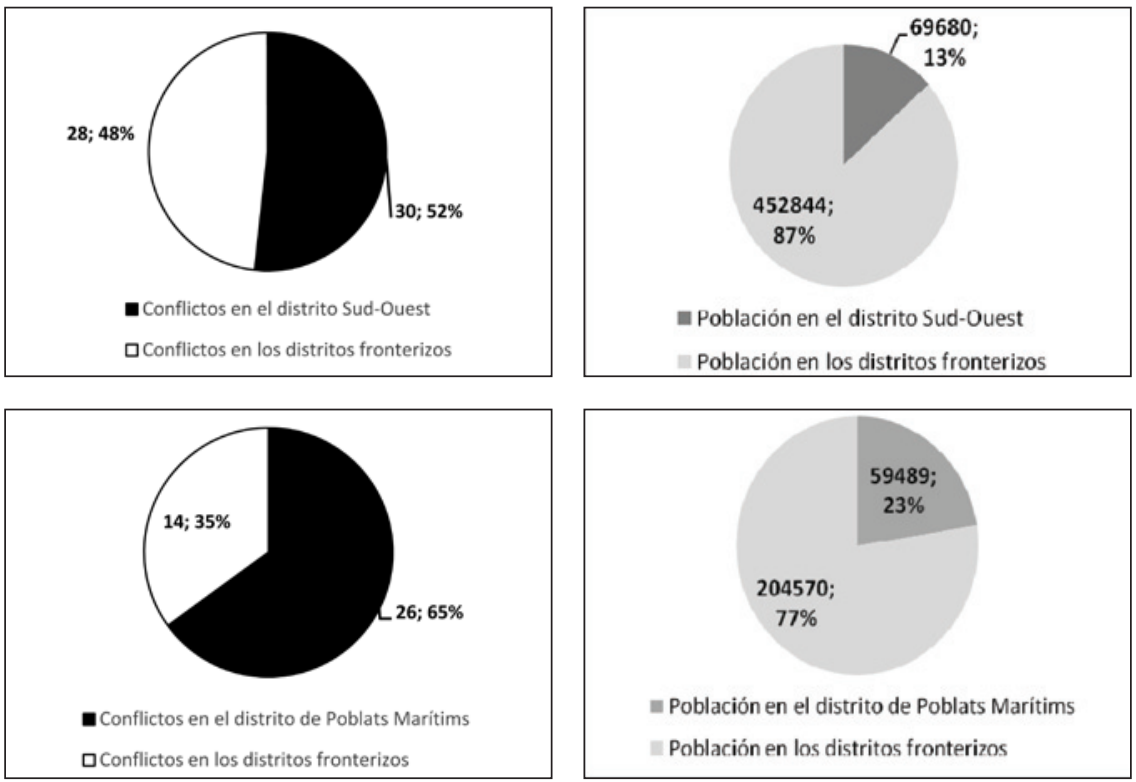

Fuente: Elaboración propia a partir de base de datos.

Si se observan los resultados de este test en el anexo, se puede apreciar como existe un vínculo estadístico significativo en las dos ciudades entre la distribución de conflictos por una parte y la densidad de población, la presencia de asociaciones ciudadanas, la tasa de paro y algunas variables de educación (personas sin estudios en Valencia y personas con estudios universitarios en Montreal) por otra. En este punto ya se puede constatar que en las dos áreas de estudio de las dos ciudades hay más conflictos en barrios con baja densidad de población (espacios industriales, portuarios, barrios históricos con menos viviendas por hectárea que la media de la ciudad o bien más viviendas vacías) así como en los barrios con más asociaciones ciudadanas, lo cual muestra la importancia de estos actores en la aparición de conflictos territoriales. La hipótesis de la mayor proliferación de conflictos en barrios urbanos y pobres se revela como muy probable ya que hay más conflictos en barrios con poca población con estudios universitarios en el caso de Montreal y en el caso de Valencia aparecen más en aquellas zonas con concentraciones significativas de población sin estudios. Además, en el caso 
de Montreal se comprueba como esta proliferación es mayor en áreas con mayores tasas de paro. En síntesis, se puede aceptar con un margen de error relativamente pequeño el supuesto de que en ambas ciudades, hay más conflictos en áreas de bajo estatus socioeconómico. Sin embargo, y sin ser ello contradictorio, es importante destacar la multicausalidad que muestra el fenónemo de los conflictos territoriales, ya que según el test realizado, otros factores intervienen como la existencia de asociaciones ciudadanas o la densidad de población.

Con el fin de ampliar el conocimiento sobre la dinámica de conflictos así como sobre sus patrones espaciales se dividieron los conflictos según tipo y se cartografiaron para cada área de estudio (figuras 8 y 9). En ambos mapas se han indicado en mayúsculas los conflictos con mayor número de artículos de prensa publicados y en cursiva los conflictos que tienen lugar en los barrios más ricos de las áreas de estudio: el corazón financiero de Montreal y el exclusivo barrio-municipio de Westmount en Montreal, así como el barrio de la ciudad de las Artes y las Ciencias y el municipio de Alboraia en Valencia.

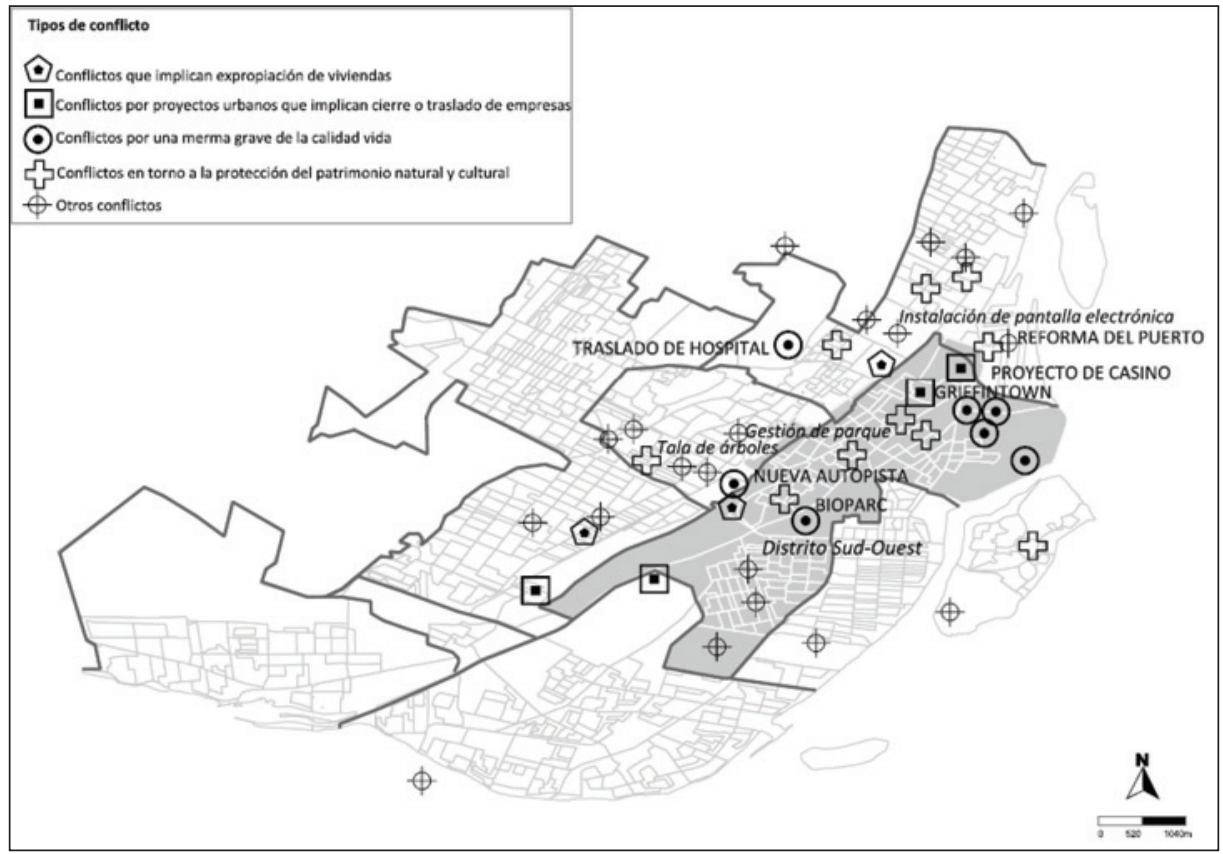

Fuente: elaboración propia a partir de base de datos sobre conflictos.

En el caso de Montreal Sud-Ouest, entre los conflictos con más artículos en prensa encontramos conflictos que implican la expropiación de viviendas como el de la modernización y ampliación del intercambiador Turcot (autopista de acceso a Montreal, 52 artículos), así como conflictos surgidos por proyectos urbanísticos que suponen el cierre o destrucción de fábricas y talleres. Este es el caso del proyecto de construcción de un moderno y exclusivo barrio de 


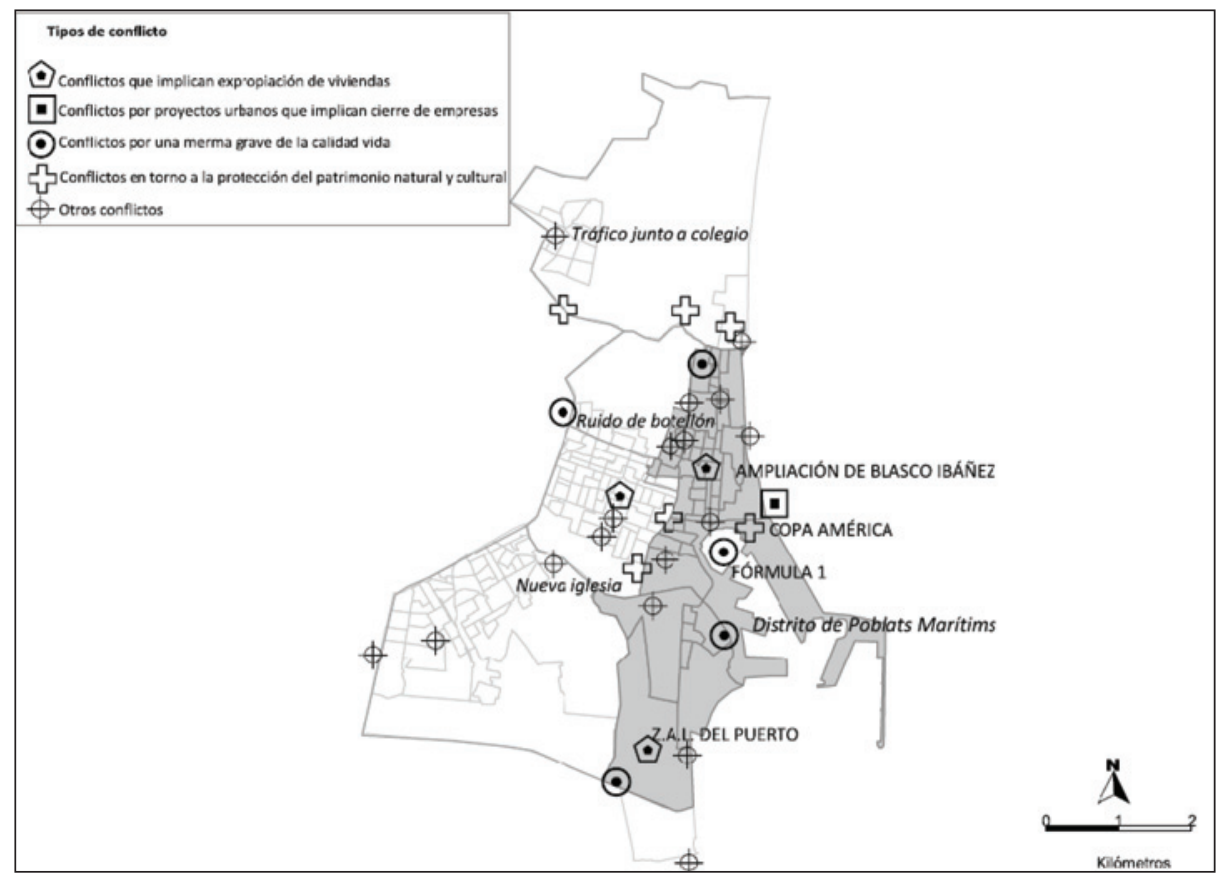

Fuente: elaboración propia a partir de base de datos sobre conflictos

oficinas y lofts en el corazón industrial del distrito (Griffintown, 65 artículos en prensa) o el cierre del centro Tri-postal de logística de correos para construir un proyecto muy similar. Entre los conflictos surgidos por sus graves implicaciones sobre la calidad de vida, destaca el proyecto Matrec de construir un ecoparque y vertedero controlado en una zona urbana (31 artículos) así como la construcción de un casino de estilo Las Vegas en el viejo puerto (51 artículos). Estos conflictos tienen como rasgos en común su importante repercursión mediática, los elevados impactos sociales y ambientales de los proyectos que originan el conflicto, y su localización dentro del distrito de Sud-Ouest. Los conflictos con más repercursión mediática que surgen en otros barrios más boyantes son la amenaza de traslado de un hospital pediátrico a otra ciudad por la fundación privada que lo gestiona (20 artículos), la instalación de una pantalla publicitaria electrónica en una calle comercial (20 artículos) o la gestión de un parque urbano en Westmount (5 artículos).

Esta misma situación se repite a grandes rasgos para el caso de Valencia-Poblats Marítims. Los conflictos más largos y con mayor repercusión mediática se concentran en el distrito de Poblats Marítims. Aquí, al contrario que en el caso de Montreal, el panorama de conflictos territoriales está claramente protagonizado por un solo conflicto: la ampliación de la avenida Blasco Ibáñez hasta el mar. Es uno de los conflictos más largos (iniciado a medi- 
ados de los noventa y aún hoy no finalizado), que solo para el periodo que nos ocupa generó 134 artículos de prensa. Es además claramente un conflicto con importantes repercusiones sociales ya que implica el deshaucio de cientos de familias y la destrucción de más de 1600 viviendas. El segundo conflicto con mayor repercusión mediática (70 artículos), también tiene como implicación la desposesión de vivienda (en este caso más que de obreros de agricultores de la huerta) y también tiene lugar en el distrito de Poblats Marítims. Se trata del conflicto surgido a raíz de la construcción de la Zona de Actividades Logísticas en el puerto sobre terrenos de huerta ocupados por decenas de viviendas, muchas de ellas de valor histórico y que fueron completamente destruidas. También los conflictos donde la pérdida de calidad de vida es un argumento utilizado tienen una importante repercusión mediática, pero mucho menor. Aquí destacan los conflictos desatados por la organización de la Copa América (36 artículos) y de la Fórmula Uno (34 artículos) en el antiguo puerto de Valencia. Los oponentes a estos proyectos critican la privatización de espacios públicos, los problemas de tráfico, contaminación y ruido, el daño sobre el patrimonio del puerto entre otras cuestiones por la celebración de estos eventos. Al igual que en el caso de Montreal, en los barrios más boyantes los conflictos son mucho menos importantes y de una tipología muy distinta. En el caso de Valencia destaca el conflicto de la Zona Acústicamente Saturada de Blasco Ibáñez (40 artículos) a causa de los ruidos y molestias que genera una calle de pubs y discotecas durante los fines de semana. Por otro lado destaca el conflicto por la reforma de la avenida del puerto en un solo sentido, a raíz de su diseño arquitectónico. En ninguno de estos barrios existen conflictos con una componente de desposesión de vivienda o de trabajo.

Una diferencia significativa entre Valencia y Montreal evidente a partir de la base de datos es que mientras que en la primera domina muy claramente el conflicto entre ciudadanos y administraciones, en el caso de Montreal además de ésta existe un importante volumen de conflictos donde se muestra una dialéctica entre sector privado y ciudadanos por el uso de la ciudad y donde aparecen los mismos argumentos con fuerza: pérdida de calidad de vida, riesgos para la salud y desestructuración del barrio. En este caso muchos conflictos se refieren a la pugna ya referida anteriormente entre por una parte promotores inmobiliarios y administración local que persigue «revitalizar» el distrito mediante diversos planes urbanísticos para construir lofts, espacios de oficinas, comerciales y de ocio sobre antiguos terrenos industriales o en áreas residenciales degradadas. En el caso de Valencia muchos de los conflictos que tienen como protagonistas a plataformas ciudadanas y administración tienen como objeto de disputa asimismo espacios públicos y elementos de patrimonio natural y cultural que están amanazados de desaparición debido a la construcción de viviendas, espacios de ocio o infraestructuras. En ambos casos aparecen con cierta frecuencia también los conflictos que surgen por los potenciales o existentes peligros para la salud y la seguridad que tienen determinados equipamientos (proyecto de Ecoparque y de vertedero en Montreal y fábrica de aceite de soja en Natzaret o perjuicios de la depuradora de Pinedo, ambos enValencia).

\section{Discusión de resultados: conflictos de pobres, conflictos de ricos}

Los conflictos territoriales son fenómenos multicausales y de gran complejidad, en el que multitud de actores con intereses divergentes entran en acción. Pese a toda esta complejidad y diversidad, a partir de la base de datos de conflictos y de su posterior análisis 
mediante estadísticas descriptivas y un test de Chi-cuadrado, es posible advertir en las áreas de estudio investigadas ciertas características comunes en muchos conflictos. El resultado del test de Chi Cuadrado muestra un rechazo de la hipótesis nula de independencia entre la distribución de conflictos y la distribución de varias variables socioeconómicas. Se encuentran diferencias significativas en las variables «población sin estudios», «población con estudios superiores»; «densidad de población», «tasas de paro»y «existencia de asociaciones», de manera que emergen más conflictos en las áreas más densas, con mayor presencia de movimientos vecinales y con mayor población sin estudios o en paro. Dicho de otra manera, el test muestra un patrón de concentración de conflictos en secciones con menor densidad de población, mayor presencia de asociaciones (vecinos, culturales, ecologistas) y de menor nivel socioeconómico (niveles bajos de educación y tasas de paro superiores a la media).

Se trata de conflictos surgidos a partir de proyectos de desarrollo urbanístico con implicaciones sociales y ambientales graves (destrucción de patrimonio, eliminación de flora, contaminación, expropiación de viviendas, cierre de empresas) y que enfrentan a ciudadanos con administraciones, en barrios pobres de ambas ciudades. Frente a estos proyectos muchos vecinos reaccionan, ya que ven amenazado su espacio de vida en todos los sentidos (vivienda, trabajo, paisaje urbano, patrimonio etc.), y ponen en marcha una serie de estrategias de resistencia y/o oposición que varían desde la protesta formal mediante ruedas de prensa o envío de cartas a responsables políticos, hasta acciones legales (denuncias) o ilegales (sentadas, okupaciones, violencia verbal o física...). En ambos distritos destaca tanto la cantidad de conflictos surgidos en apenas quince años como el protagonismo de una dialéctica por una parte entre vecinos que reclaman mantener una calidad de vida, unos espacios públicos y un patrimonio natural y cultural y por otra unas administraciones que aprueban o apoyan planes con el argumento de revitalizar la zona o propiciar un cierto desarrollo económico en estas áreas deprimidas, pese a las transfromaciones físicas radicales que estos planes suponen. Un buen ejemplo son los conflictos que surgen como respuesta a proyectos que implican desposesión directa de vivienda (conflicto del Cabanyal y de la ZAL en Valencia), de trabajo (cierre de las empresas Imperial Tobacco y CN de material ferroviario en Montreal para construir lofts) o de calidad de vida y muestran la existencia de un incipiente proceso de gentrificación en algunos barrios de estos distritos, ya que algunos son propicios a este fenómeno (espacios industriales vacíos, suelo barato, parque de viviendas degradado y potencial inmobiliario por su cercanía al centro, vistas al mar o río y patrimonio histórico) (Lees et al, 2008). Otro ejemplo son los conflictos que enfrentan a administraciones y colectivos en exclusión o criminalizados (okupas sobre todo, y en algún caso vagabundos o prostitutas). En estos conflictos surge como argumento de movilización el derecho a una vivienda o simplemente a existir en la ciudad de estos colectivos frente a los discursos de administraciones y parte de la ciudadanía que defiende que estos colectivos degradan el espacio público. Se trata de conflictos de menor intensidad, pero que entran en la dialéctica entre gobernantes y gobernados por modelos de ciudad casi antagónicos.

Se podría hablar con ciertos matices, de conflictos de ricos y conflictos de pobres. Mientras que los conflictos que surgen en barrios de nivel socioeconómico medio o alto surgen por problemas relativamente graves de ruido, estética o conflictos de tipo NIMBY 
por la planificación de equipamientos (ZAL de Blasco Ibáñez, paneles electrónicos o restauración de un antiguo hotel en el centro de Montreal), en los casos de los barrios degradados, los proyectos que generan conflictos suponen en algunos casos la transformación radical del espacio urbano (Griffintown en Montreal o el Cabanyal en Valencia), o surgen no ya por motivos estéticos, sino por los problemas de salud que pueden generar (fábrica de aceites en Natzaret, depuradora de Pinedo o ecoparque en el Sud-Ouest de Montreal). En ambas ciudades además los puertos juegan un papel de auténticos generadores de conflictos, por la cantidad y envergadura de proyectos urbanos o de expansión portuaria que amenazan elementos de patrimonio, viviendas o áreas seminaturales, y en ambos casos podría afirmarse que dificulta la efectiva integración en sus respectivas tramas urbanas. No solamente se localizan en estas áreas los proyectos con mayores impactos, sino que son auténticos acumuladores de conflictos. Un caso paradigmático es el de Pinedo en Valencia, pedanías de apenas 2700 habitantes donde a lo largo de los últimos quince años han surgido conflictos por la ampliación del puerto que destruye casas y campos, la contaminación y malos olores de la depuradora, la contaminación del PN de l’Albufera o la ampliación del puerto deportivo que afecta a la playa y las áreas tradicionales de pesca de esta pedanía. Esta pedanía contrasta con el caso del cercano y boyante barrio de Monteolivete, junto a la ciudad de las Artes y las Ciencias, con más de 20000 habitantes y también en la periferia de la ciudad, en el que no se desarrolla ningún conflicto ni proyecto urbanístico con impactos territoriales en los últimos quince años. Una comparación similar existe por una parte entre el barrio de Pointe-Saint-Charles en el distrito Sud-Ouest y el barrio de Île-des-Soeurs de clases medias, dentro del distrito de Verdun en Montreal, de 18000 habitantes. En el caso de Île-des-Soeurs tan solo surgen un par de conflictos relacionados con la conservación de una estación de servicio diseñada por Mies Van der Rohe y por la altura excesiva un proyecto de torre de apartamentos, mientras que en el histórico barrio de Point-Saint-Charles de apenas 13000 habitantes se concentran conflictos de gran impacto, como el ya mencionado proyecto de Ecoparc, el cierre de la fábrica de material ferroviario para convertirla en apartamentos o parte del proyecto de Griffintown.

Frente a esta realidad de eclosión de conflictos uno de los debates que convendría abordar en contribuciones futuras es el papel que desempeñan los conflictos en la construcción de la ciudad y la consolidación de la ciudadanía como actor con un creciente protagonismo en la gobernanza de la ciudad en las últimas décadas. Compartimos la visión de Delgado de que «el conflicto antagonista no puede concebirse como una estridencia o patología» (Delgado, 2011:30). En este sentido el conflicto se convierte en una estrategia necesaria de presión, una voz discordante frente a los discursos dominantes sobre como usar o planificar el espacio público, en especial en los «bordes»o «territorios indecisos» de la ciudad (Borja, 2003), como es el caso de Poblats Marítims y Sud-Ouest. Muchos de los conflictos territoriales estudiados en estos dos casos evidencian no solamente la necesidad de revisar en profundidad los mecanismos de concertación con la ciudadanía, en especial de aquellos barrios que ya de por sí presentan graves problemas de desempleo y exclusión social, sino también la propia manera de planificar la ciudad con proyectos segregadores, destructores de patrimonio y desestructuradores de barrios que tienden a concentrarse no precisamente en los barrios más boyantes (grandes eventos, infraestructuras, proyectos de revitalización). 
En algunos casos de conflictos podría hablarse incluso de una lucha de clases renovada no simétrica (al contrario que los conflictos capital-trabajo clásicos en la ciudad industrial), entre por una parte proyectos urbanísticos defendidos por una élites transnacionales y locales (caso del Casino del Cirque du Soleil en Montreal o con matices los grandes eventos en Valencia) y rechazados por amplias capas de las clases urbanas obreras, pobres o empobrecidas que ven amenazados, no ya su nivel de bienestar, sino su propio derecho a existir en la ciudad, ya que muchos de estos proyectos terminan expulsando a población (expropiaciones de viviendas, empresas y destrucción de espacios de vida). Ampliar estos debates con más precisión y ahondar en la comparación entre conflictos en distintas ciudades son tareas que han de ser abordadas en el futuro para entender mejor cómo surgen y evolucionan los conflictos, y como muchos de ellos acaban siendo una pieza clave en la construcción de la ciudad y de una ciudadanía más cohesionada.

\section{CONCLUSIONES}

Esta contribución ha pretendido abrir nuevas líneas de estudio al análisis de conflictos territoriales. La mayor parte de la producción científica en este campo se dedica al análisis pormenorizado de un conflicto territorial o al estudio más o menos sistemático de conflictos territoriales en un espacio urbano acotado. Aquí se ha intentado introducir al menos dos aspectos poco explotados en este tipo de estudios: el análisis comparativo sistemático de los conflictos territoriales surgidos en un periodo de tiempo en dos ciudades bien distintas y su interpretación desde la geografía crítica, como un fenómeno con un fuerte componente espacial.

Tanto el distrito de Sud-Ouest en Montreal como el de Poblats Marítims en Valencia comparten las características de ser barrios que han experimentado en años pasados un gran dinamismo constructivo, contienen importantes contingentes de población pobre, tradición obrera y multitud de conflictos territoriales. A partir de la elaboración de una base de datos sobre conflictos urbanos y un análisis estadístico entre la distribución de conflictos y la de determinadas variables socioeconómicas es posible afirmar primeramente que los conflictos no aparecen aleatoriamente en el territorio, en segundo lugar que éstos se concentran en las zonas de mayor pobreza, y en tercer lugar que estos conflictos surgen como reacción a importantes proyectos de transformación de la ciudad que implican desposesión de espacio vital o calidad de vida. Por todo ello se pueden interpretar como una expresión de lucha y resistencia no institucionalizada frente a la manera de planificar y gobernar la ciudad.

Por una parte los habitantes de estos distritos desean mantener un cierto nivel de bienestar o incrementarlo. Defienden un derecho a la ciudad y la protección de la vida de barrio y de su patrimonio construido y del medio ambiente. Por otra parte diversos actores económicos e institucionales presionan para « renovar » $\mathrm{y}$ « revitalizar » estos barrios para mejorar la imagen de la ciudad en el exterior y generar más riqueza a través de ambiciosos proyectos urbanísticos de construcción de viviendas difícilmente asequibles para la población residente, lo cual implicaría un reemplazo de la población a medio plazo de estos barrios por población de mayores recursos. Es lo que en palabras de Harvey constituye un ejemplo desposesión de espacio vital y calidad de vida de las clases populares en la ciudad por parte de las élites burguesas, una desposesión por el bien de la acumulación en esta nueva fase de capitalismo globalizado. 


\section{ANEXO: TEST DE CHI-CUADRADO}

Para el caso de Valencia se utilizaron indicadores estadísticos a nivel de sección ofrecidos por el censo de 2001, el último disponible, mientras que para el caso de Montreal se utilizaron las « áreas de difusión » (unidades espaciales censales equivalentes a secciones de máximo 2000 habitantes) también del último censo publicado, el de 2001. Las variables escogidas se dividieron en variables geográficas y socioeconómicas. Comenzando por las primeras:

- Densidad demográfica: habitantes $/ \mathrm{km}^{2}$ en cada sección o área de difusión

- Bienes patrimoniales: como indicador comparable se escogió la proporción de edificios construidos antes de 1960 por sección o área de difusión

- Tasa de paro: Tasa de paro en 2001 a nivel de sección en Valencia o área de difusión en Montreal.

- Nivel de ingresos: Ingreso medio por familia en Montreal e índice sintético de renta en Valencia.

- Nivel de instrucción: En este apartado se utilizan dos variables distintas, el porcentaje de población sin estudios (sin certificado escolar) y el porcentaje de población con estudios universitarios.

- Porcentaje de familias monoparentales: Porcentaje de familias monoparentales por sección o área de difusión.

- Presencia de asociaciones de barrio y ciudadanas: Número de asociaciones de carácter social, cultural o de defensa de derechos o de vecinos inscritas en el registro local por sección o área de difusión.

Para estudiar la influencia de cada variable sobre la distribución de conflictos es necesario construir una tabla de contingencia donde las variables son subdivididas en tres clases: inferior a la media regional, igual a la media regional y superior a la media regional. La media regional es el resultado de una ponderación de los valores de la variable en cada sección con la población residente, ya que existen importantes variaciones de población entre secciones.

Media regional $=\frac{\sum_{i=1} v_{i} p_{i}}{P o b}$

$v_{i}$ valor de la variable en el sector $i$

$p_{i}$ población en el sector $i$

Pob población de todos los sectores

Si la hipótesis planteada es correcta, debería haber un reparto similar entre conflictos territoriales en las diferentes secciones que conforman las áreas de estudio y la distribución de la población pobre (secciones con porcentajes significativos de población sin estudios, sin empleo y con rentas bajas). Por otro lado, si la distribución de conflictos es similar a la distribución de la población en general (si existe un número similar de conflictos tanto en barrios de rentas altas como de rentas bajas), en ese caso la distribución de conflictos sería independiente a la distribución de la población de bajos recursos en el territorio y por lo tanto no existiría ningún vínculo entre ambas variables. Los resultados del chi cuadrado muestran si las dos distribuciones (conflictos respecto a cada variable) son o no significativamente diferentes. 
Cuadro 5

RESULTADOS DEL TEST DE INDEPENDENCIA ENTRE LA DISTRIBUCIÓN DE CONFLICTOS Y LAS VARIABLES CONSIDERADAS. VO: VALORES OBSERVADOS; VE: VALORES ESPERADOS; I: INFERIOR A LA MEDIA REGIONAL; M: IGUAL A LA MEDIA REGIONAL; S: SUPERIOR A LA MEDIA REGIONAL.

$X^{2}$ : CHI CUADRADO DE PEARSON. EN NEGRITA $<0,05$

\begin{tabular}{|c|c|c|c|c|c|c|c|c|c|c|c|}
\hline \multicolumn{6}{|c|}{ Valencia } & \multicolumn{6}{|c|}{ Montreal } \\
\hline & Población & VO & $\mathbf{V E}$ & Diferencia & $X^{2}$ & & Población & VO & $\mathbf{V E}$ & Diferencia & $X^{2}$ \\
\hline \multicolumn{6}{|c|}{ Población sin estudios } & \multicolumn{6}{|c|}{ Población sin estudios } \\
\hline I & 117328 & 23 & 33 & $-10,02$ & & I & 165991 & 31 & 29 & 2,16 & \\
\hline $\mathbf{M}$ & 46325 & 20 & 13 & 6,96 & 7,25 & $\mathbf{M}$ & 88217 & 7 & 15 & $-8,33$ & 5,87 \\
\hline $\mathbf{S}$ & 67349 & 22 & 19 & 3,04 & & $\mathbf{S}$ & 183253 & 38 & 32 & 6,16 & \\
\hline \multicolumn{6}{|c|}{ Población con estudios universitarios } & \multicolumn{6}{|c|}{ Población con estudios universitarios } \\
\hline $\mathbf{I}$ & 112518 & 37 & 31 & 5,50 & & I & 205544 & 48 & 40 & 8,05 & \\
\hline $\mathbf{M}$ & 46603 & 12 & 13 & $-1,04$ & 2,02 & $\mathbf{M}$ & 83679 & 6 & 16 & $-10,26$ & 8,26 \\
\hline $\mathbf{S}$ & 73154 & 16 & 20 & $-4,48$ & & $\mathbf{S}$ & 153308 & 32 & 30 & 2,20 & \\
\hline \multicolumn{6}{|c|}{ Densidad de población } & \multicolumn{6}{|c|}{ Densidad de población } \\
\hline I & 99154 & 44 & 28 & 16,09 & & I & 257918 & 71 & 47 & 24,36 & \\
\hline M & 52317 & 12 & 15 & $-2,72$ & 17,78 & M & 76755 & 5 & 14 & $-8,88$ & 31,4 \\
\hline $\mathbf{S}$ & 79531 & 9 & 22 & $-13,38$ & & $\mathbf{S}$ & 102326 & 3 & 18 & $-15,50$ & \\
\hline \multicolumn{6}{|c|}{ Tasa de paro } & \multicolumn{6}{|c|}{ Tasa de paro } \\
\hline I & 107986 & 23 & 30 & $-7,39$ & & I & 207505 & 50 & 40 & 9,66 & \\
\hline M & 45023 & 18 & 13 & 5,33 & 4,23 & M & 95522 & 19 & 19 & 0,43 & 6,10 \\
\hline $\mathbf{S}$ & 77993 & 24 & 22 & 2,05 & & $\mathbf{S}$ & 139504 & 17 & 27 & $-10,11$ & \\
\hline \multicolumn{6}{|c|}{ Año de construcción de edificios } & \multicolumn{6}{|c|}{ Año de construcción de edificios } \\
\hline $\mathbf{I}$ & 82098 & 20 & 23 & $-3,11$ & & I & 126663 & 20 & 23 & $-2,53$ & \\
\hline $\mathbf{M}$ & 45427 & 19 & 13 & 6,21 & 3,77 & M & 81756 & 22 & 15 & 7,46 & 4,70 \\
\hline $\mathbf{S}$ & 103477 & 26 & 29 & $-3,12$ & & $\mathbf{S}$ & 230242 & 36 & 41 & $-4,95$ & \\
\hline \multicolumn{6}{|c|}{ Renta } & \multicolumn{6}{|c|}{ Renta } \\
\hline $\mathbf{I}$ & 88795 & 28 & 25 & 3,01 & & I & 270566 & 40 & 48 & $-8,41$ & \\
\hline M & 48835 & 13 & 14 & $-0,74$ & 0,60 & M & 77945 & 18 & 14 & 4,05 & 3,84 \\
\hline $\mathbf{S}$ & 93372 & 24 & 26 & $-2,28$ & & $\mathbf{S}$ & 87522 & 20 & 16 & 4,34 & \\
\hline \multicolumn{6}{|c|}{ Número de asociaciones ciudadanas } & \multicolumn{6}{|c|}{ Número de asociaciones ciudadanas } \\
\hline I & 163585 & 31 & 46 & $-15,04$ & & I & 415454 & 67 & 74 & $-6,76$ & \\
\hline M & 58199 & 31 & 16 & 14,62 & 18,02 & $\mathbf{M}$ & 19370 & 9 & 3 & 5,56 & 11,3 \\
\hline $\mathbf{S}$ & 9218 & 3 & 3 & 0,41 & & $\mathbf{S}$ & 4609 & 2 & 1 & 1,18 & \\
\hline \multicolumn{6}{|c|}{ Familias monoparentales } & \multicolumn{6}{|c|}{ Familias monoparentales } \\
\hline $\mathbf{I}$ & 95688 & 28 & 27 & 1,07 & & I & 188963 & 42 & 37 & 5,27 & \\
\hline M & 51824 & 10 & 15 & $-4,59$ & 2 & M & 93734 & 14 & 18 & $-4,22$ & 5,99 \\
\hline $\mathbf{S}$ & 83490 & 27 & 24 & 3,50 & & $\mathbf{S}$ & 159834 & 30 & 31 & $-1,07$ & \\
\hline
\end{tabular}




\section{BIBLIOGRAFÍA}

ALBERDI, J. et al. (2002): «Una reflexión sobre la acción colectiva «Nimby»: El caso Hontza», Inguruak, 33: 59-80.

AZNAR, O. et al.;(2006) «Quels indicateurs mobiliser pour les politiques environnementales locales?», Géographie, économie, société 3/2006 (Volume 8), p.369-384.

BLASCO IBÁÑEZ, V. (1944): Flor de Mayo. Valencia: Ed. Prometeo, 286p.

BORJA, J. La ciudad conquistada. Barcelona: Alianza Editorial, 2003, 384 pp.

BRENNER, N. y THEODORE, N (2002) : Cities and Geographies of «Actually existing neoliberalism». En: BRENNER, Neil y THEODORE, Nik (Ed.) Spaces of neoliberalism. Urban restructuring in North America and Western Europe. Londres: Blackwell Publishers, pp. 1-33.

BRENNER, N. (2004): New State spaces: urban governance and the rescaling of statehoof. Oxford: Oxford University Press, 2004, 351 p.

BRION, D.J. (1988): An Essay on LULU, NIMBY, and the problem of distributive Justice. 15 Boston College of Environmental Affairs Law Review 437 (1988)

CAPEL, H. y LINTEAU, P.A. (1998): Barcelona-Montreal. Desarrollo urbano comparado. Barcelona: Publicacions de la Universitat de Barcelona, 1998.

CASTELLS, M. (1977): La cuestión urbana. México: Siglo XXI.

CASTELLS, M. (1997): La era de la información: economía, sociedad y cultura. México: Siglo Veintiuno.

COX, K. R., (1978) (dir): Urbanization and conflict in market societies.

London, RU: Methuen.

DACHEVSKY, M. (2001): Urban zapping: ciudades, productos y marcas. Barcelona, Ediciones de la UPC, $174 \mathrm{p}$.

DEAR, M. y LONG, J. (1978): Community strategies in locational conflict. En Cox, K.R.: Urbanization and conflict in market societies, London: Methuen, 113-128,

DELGADO, M. (2011): El espacio público como ideología. Madrid: Libros de la Catarata, $120 \mathrm{p}$.

GAVIRIA, M. (1969): Prólogo a El derecho a la ciudad. En Lefebvre, El derecho a la ciudad. Barcelona: Ediciones Península, 1969, 169 p.

HARVEY, D. (1976): Labor, capital and class struggle around the built environment in advanced capitalist societies. Politics \& Society, vol. 6 no. 3 , p. 265-295

HARVEY, D. (2003): The right to the city. International Journal of Urban and Regional Research, Vol. 27: 939-941.

HARVEY, D. (1973): Social justice and the city, Atlanta: Georgia Univ. Press, 354 p.

JOERIN, F et al. (2005) : Analyse spatiale des conflits urbains. Enjeux et contextes dans la région de Québec. Cahiers de Géographie du Québec 49(138): 319-342.

KOHLER, B. y WISSEN, M. (2005) : Glocalizing protest: urban conflicts and global social movements. En Lin, J y Mele, C. (Ed.): The urban sociology reader. Oxon (RU): Routledge, 2005, p.346-355

LEES, L.; SLATER, T. y WYLY, E. (2008): Gentrification. London: Routledge, 310 p.

LEFEBVRE, H. (1969): El derecho a la ciudad. Barcelona: Ed. Península, 169 pp. 
LOBER, D. J. (1995): «Why protest: Public behavioral and attitudinal response to siting a waste disposal facility.» Policy Studies Journal 23:499-518

MAC LEOD, G. (2002): From urban entrepreneurialism to a «revanchist city»?. On the spatial injustices of Glasgow's renaissance. En: BRENNER, Neil y THEODORE, Nik. (Ed.) Spaces of neoliberalism. Urban restructuring in North America and Western Europe. Londres: Blackwell Publishers, 2002, pp. 254-277.

MARCUSE, P. (1989): 'Dual city': a muddy metaphor for a quartered city. International Journal of Urban and Regional Research, Vol. 13, pp. 697-708.

MARCUSE, P. (1993): What's So New About Divided Cities?. International Journal of Urban and Regional Research, Vol. 17, 1993, pp. 355-365.

MARCUSE, P. y VAN KEMPEN, R. (2000): Globalizing cities. A new spatial order?. Malden (EE.UU.): Blackwell Publishing Ltd, 2000, 319 p.

MINTON, A. (2009): Ground control. Fear and happiness in the twenty-first century city. Londres: Penguin Books, 240 p.

NEL·LO, O. (2003): Aquí no! Conflictes territorials a Catalunya. Barcelona, ed. Empúries., $461 \mathrm{p}$.

PINNEL, Y. (2005): Rapport sur la pauvreté à Montréal. Voix populaire de St Henri. 20 février, 2005.

RUTHERFORD, P.F.W (1897): The city below the Hill. Toronto: University of Toronto Press, 1897.

TRUDELlE, C. et al: (2006). Becoming Visible: Women and Conflicts in the Quebec Metropolitan Areas,1965-2000. Urban Studies, Vol. 43, No. 12, 2183-2203, noviembre de 2006

WOLSINK, M. (1994): «Entanglement of Interests and Motives - Assumptions Behind the Nimby-Theory on Facility Siting.» Urban Studies 31:851-866

ZUKIN, S. (1995): The culture of cities. New York: Blackwell Publishing, 1995.

\section{FUENTES}

INSTITUTO NACIONAL DE ESTADÍSTICA (2001), «Censo de población y viviendas de 2001». En línea: <www.ine.es>

UQAM (2010), Hemeroteca digital de los diarios La Presse y Le Devoir. Consulta de noticias del periodo 1995-2010 en <http://www.bibliotheques.uqam.ca>

LAS PROVINCIAS (1995-2010), Consulta de ejemplares en hemeroteca de Valencia y en $<$ www.levante-emv.es>

LEVANTE (1995-2010): Consulta de ejemplares en hemeroteca de Valencia y en <www. levante-emv.es >

STATISTIQUE CANADA (2001): «Recensement 2001». En línea: <http://www12.statcan. $\mathrm{ca} /$ francais/census01/home/index.cfm> 